\title{
A novel approach for establishing cardiovascular drug efficacy
}

\author{
Hiddo. J. Lambers Heerspink, Diederick E. Grobbee and Dick de Zeeuw
}

Gaining an early understanding of the likely ultimate efficacy of drugs is crucial for the pharmaceutical industry, as lack of efficacy remains a major reason for attrition in the later stages of drug development (Phase II and Phase III attrition rates 2011-2012. Nature Rev. Drug Discov. 12, 569; 2013) ${ }^{1}$. Drug development for cardiovascular and/ or renal diseases is currently often based on the modification of a single risk factor, such as blood pressure or lipid profiles, with the expectation that this will decrease the long-term risk of morbidity or mortality. Thus, the risk factor serves as a surrogate for the intended effect. To confirm that the drug effect on the risk factor indeed leads to the expected long-term efficacy and safety, short-term trials focused on effects on the risk factor are (or should be) followed by one or more (post-registration) trials evaluating clinically meaningful outcomes, such as reduction in cardiovascular events, which are typically large, complex and expensive. In parallel to this process to investigate efficacy, the safety of the drug is established by monitoring a mostly fixed set of parameters in all efficacy trials.

\section{Off-target drug effects}

Current drug discovery and development for indications such as hypertension assumes two things; first, that the drug-induced change in an on-target risk factor, such as blood pressure, is the most important contributor to the anticipated reduction in cardiovascular/renal risk. Hence, the ontarget drug effect should explain the drug effect on long-term outcome ${ }^{2}$. Second, it is assumed that the drug has no other effects that influence long-term outcome.

Although drug effects on blood pressure or cholesterol are important drivers of cardiovascular/renal risk reduction, we should recognize that drugs often have effects on other parameters (off-target effects), which may also be risk factors that contribute to long-term outcome, either in a positive or negative way. Indeed, many drugs currently used in cardiovascular/renal risk management have multiple effects on risk factors.

For example, angiotensin-converting enzyme inhibitors (ACEIs) or angiotensin receptor blockers (ARBs) are registered for blood pressure lowering (their on-target effect), but also decrease urinary albumin excretion (an off-target effect). The albuminuria reduction induced by ACEIs or ARBs also reduces renal and cardiovascular risk, and thus amplifies the long-term on-target effect $^{3-5}$. In addition to their cholesterollowering effects, statins decrease C-reactive protein (CRP) or albuminuria, which may contribute to cardiovascular protection ${ }^{6-8}$. Metformin improves markers of endothelial function independent of favourable changes in glycaemic control ${ }^{9}$. Sodium glucose co-transport inhibitors seem to exert multiple effects: they lower blood glucose, but also decrease blood pressure, body weight, and albuminuria, which may all contribute to long-term cardiovascular/renal protection $^{10,11}$.

In the above examples, the off-target effect (or effects) amplify the on-target effect on organ protection. However, the off-target effect (or effects) may also offset the cardiovascular/renal protection. For example, ARBs increase serum potassium, leading to hyperkalaemia, and a study suggested that the increase in serum potassium blunted the renoprotective efficacy of the ARB losartan ${ }^{12}$.

\section{Implications for drug development}

There are two important issues with continuing to pursue cardiovascular/renal drug development strategies that focus on modifying single risk factors without due consideration of off-target effects. First, focusing only on the on-target effect could lead to underestimation of the true longterm drug effect by ignoring beneficial off-target effects. Second, and more concerning, by focusing solely on the on-target effect, potential long-term harmful effects may be overlooked in cases where adverse off-target effects override the beneficial on-target effect.

Providing an example of the first scenario, Hou and colleagues showed that titrating the dose of an ACEI or an ARB to the maximal albuminuria-lowering dose lowered blood pressure (the on-target marker) similarly to the maximal antihypertensive dose but resulted in a markedly larger renoprotective effect $^{13}$. Another example was provided by the PLANET trials, which compared the effects of atorvastatin and rosuvastatin on renal function; the drugs seemed to decrease levels of LDL cholesterol to a similar extent but had different effects on kidney disease progression ${ }^{7}$. So, solely relying on the on-target drug effect may provide a false impression of the actual drug effect on renal or cardiovascular outcomes.

With respect to the second scenario, in the past 5 years, several large late-stage drug trials and even post-marketing studies have reported no effect or even harmful effects on clinically meaningful outcomes, despite the drug having shown promising beneficial effects on the on-target cardiovascular/renal risk factor, probably owing to off-target drug effects (TABLE 1; Supplementary information S1 (table); Supplementary information S2 (box)). For example, off-target effects with dual blockade of the renin-angiotensinaldosterone system (RAAS) include induction of hyperkalaemia, which may increase cardiovascular risk and blunt the cardioprotective effect $^{14}$.

These examples illustrate that not accounting for off-target drug effects has severe consequences: patients may be unnecessarily exposed to ineffective or even harmful drugs; in cases where such drugs reach the market, public trust in the drug regulatory and healthcare system may be eroded, and inaccurate prediction of ultimate drug efficacy means that companies invest resources in expensive failures.

\section{Can we solve the problem?}

Major mind-shifts by the different stakeholders involved in drug development and registration are needed before we can start addressing this problem. The artificial division into efficacy on the one hand and safety on the other has led to the false assumption that drug safety parameters contribute only marginally to the long-term efficacy outcome. As an example, the blood pressure (on-target) effects of drugs that intervene in the RAAS are classified under the efficacy paragraph in the drug labelling, whereas the (off-target) effects on albuminuria and potassium are listed in the safety sections.

So, we should consider drugs for cardiovascular/renal diseases as therapies with multiple effects, which could be either good or bad for long-term cardiovascular/ renal disease prevention, and classify drugs based on their ultimate (long-term) intention and not on the short-term surrogate. In other words, we should not classify a drug as a 
Table 1 | Selected studies of drugs that failed to provide additional cardiovascular/renal protection

\begin{tabular}{|c|c|c|c|c|c|c|}
\hline Trial acronym* & Population & Treatment & $\begin{array}{l}\text { Primary } \\
\text { endpoint }\end{array}$ & $\begin{array}{l}\text { On-target } \\
\text { effect }\end{array}$ & Off-target effects ${ }^{\ddagger}$ & Comment \\
\hline \multicolumn{7}{|l|}{ Blood pressure } \\
\hline $\begin{array}{l}\text { ONTARGET } \\
(2008 ; N=25,620)\end{array}$ & High CV risk & $\begin{array}{l}\text { Telmisartan and } \\
\text { ramipril versus } \\
\text { telmisartan or ramipril }\end{array}$ & $\begin{array}{l}\text { CV } \\
\text { outcome }\end{array}$ & $\begin{array}{l}\text { Blood } \\
\text { pressure }\end{array}$ & $\begin{array}{l}\text { Hyperkalaemia, } \\
\text { hypotension, }\end{array}$ & $\begin{array}{l}\text { No CV protection with } \\
\text { combination therapy }\end{array}$ \\
\hline $\begin{array}{l}\text { ALTITUDE } \\
(2011 ; N=8561)\end{array}$ & $\begin{array}{l}\text { Type } 2 \text { diabetes } \\
\text { and renal or } \mathrm{CV} \\
\text { disease }\end{array}$ & $\begin{array}{l}\text { Aliskiren versus } \\
\text { placebo on } \\
\text { background of RAASi }\end{array}$ & $\begin{array}{l}\text { Renal/CV } \\
\text { outcome }\end{array}$ & $\begin{array}{l}\text { Blood } \\
\text { pressure }\end{array}$ & $\begin{array}{l}\text { Hyperkalaemia, } \\
\text { hypotension }\end{array}$ & $\begin{array}{l}\text { Trial terminated early } \\
\text { owing to an increased rate } \\
\text { of stroke, acute kidney } \\
\text { injury, and hyperkalaemia }\end{array}$ \\
\hline $\begin{array}{l}\text { VA-NEPHRON-D } \\
(2013 ; N=1850)\end{array}$ & $\begin{array}{l}\text { Type } 2 \text { diabetes } \\
\text { and nephropathy }\end{array}$ & $\begin{array}{l}\text { Losartan and } \\
\text { lisinopril versus } \\
\text { losartan }\end{array}$ & $\begin{array}{l}\text { Renal } \\
\text { outcome }\end{array}$ & $\begin{array}{l}\text { Blood } \\
\text { pressure }\end{array}$ & Hyperkalaemia & $\begin{array}{l}\text { Trial terminated early } \\
\text { owing to futility and excess } \\
\text { of hyperkalaemia and } \\
\text { acute kidney injury }\end{array}$ \\
\hline $\begin{array}{l}\text { ASCEND } \\
(2008 ; N=1392)\end{array}$ & $\begin{array}{l}\text { Type } 2 \text { diabetes } \\
\text { and nephropathy }\end{array}$ & $\begin{array}{l}\text { Avosentan versus } \\
\text { placebo on } \\
\text { background of RAASi }\end{array}$ & $\begin{array}{l}\text { Renal } \\
\text { outcome }\end{array}$ & $\begin{array}{l}\text { Blood } \\
\text { pressure, } \\
\text { albuminuria }\end{array}$ & $\begin{array}{l}\text { Sodium retention } \rightarrow \text { body } \\
\text { weight increase; } \mathrm{Hb} \\
\text { decrease }\end{array}$ & $\begin{array}{l}\text { Trial terminated early } \\
\text { owing to increased rate } \\
\text { of CHF }\end{array}$ \\
\hline $\begin{array}{l}\text { DAL-CEP } \\
(2012 ; N=15,871)\end{array}$ & $\begin{array}{l}\text { Recent acute } \\
\text { coronary } \\
\text { syndrome }\end{array}$ & $\begin{array}{l}\text { Dalcetrapib } \\
\text { versus placebo on } \\
\text { background of } \\
\text { statin therapy }\end{array}$ & $\begin{array}{l}\text { CV } \\
\text { outcome }\end{array}$ & $\begin{array}{l}\mathrm{HDL} \\
\text { cholesterol }\end{array}$ & $\begin{array}{l}\text { Hypertension, increased } \\
\text { C-reactive protein }\end{array}$ & $\begin{array}{l}\text { Trial terminated early } \\
\text { owing to futility }\end{array}$ \\
\hline $\begin{array}{l}\text { HPS2-THRIVE } \\
(2013 ; N=25,673)\end{array}$ & $\begin{array}{l}\text { CV disease history } \\
\text { or diabetes }\end{array}$ & $\begin{array}{l}\text { Niacin/laropiprant } \\
\text { versus placebo on } \\
\text { background of statin } \\
\text { or statin/ezetimibe }\end{array}$ & $\begin{array}{l}\text { CV } \\
\text { outcome }\end{array}$ & $\begin{array}{l}\mathrm{HDL} \\
\text { cholesterol }\end{array}$ & $\begin{array}{l}\text { Hyperuricaemia, } \\
\text { hyperglycaemia }\end{array}$ & $\begin{array}{l}\text { Trial terminated early } \\
\text { owing to futility and } \\
\text { increased rate of bleeding } \\
\text { (gut and brain) }\end{array}$ \\
\hline
\end{tabular}

$H b A 1 c^{\varsigma}$

Meta-analysis

of rosiglitazone

trials (2010)

\section{ALECARDIO}

(2013; $N=7228)$

Type 2 diabetes

Rosiglitazone versus control therapy

CV outcome

$\mathrm{HbA1c}$

CV/renal HbA1c outcome

Aleglitazar versus placebo with acute coronary syndrome

ORIGIN

(2012; $N=12,537)$

(Pre-)diabetes at

Insuline glargine versus placebo

\section{CV} outcome

$\mathrm{HbA1c}$

HbA1c

\section{Body}

outcome

\section{Body weight}

SCOUT

(2010; $N=9,804)$

$\begin{array}{ll}\text { Obese/ } & \text { Sibutramine versus } \\ \text { overweight at CV } & \text { placebo }\end{array}$
decrease

\section{Sodium retention $\rightarrow$ body}

Rosiglitazone EU marketing authorization was suspended owing to increased rate of $\mathrm{Ml}$ and $\mathrm{CHF}$

Trial terminated early owing to increased rate of CHF, bone fractures, Gl-bleedings and futility weight increase, $\mathrm{H}$ decrease

No CV protection with insuline glargine

risk

\section{Serum creatinine}

\begin{tabular}{|c|c|c|c|c|c|c|}
\hline $\begin{array}{l}\text { BEACON } \\
(2013 ; N=2185)\end{array}$ & $\begin{array}{l}\text { Type } 2 \text { diabetes } \\
\text { and chronic } \\
\text { kidney disease }\end{array}$ & $\begin{array}{l}\text { Bardoxolone-methyl } \\
\text { versus placebo on } \\
\text { background of RAASi }\end{array}$ & $\begin{array}{l}\text { Renal } \\
\text { outcome }\end{array}$ & $\begin{array}{l}\text { Serum } \\
\text { creatinine }\end{array}$ & $\begin{array}{l}\text { Blood pressure, } \\
\text { albuminuria }\end{array}$ & $\begin{array}{l}\text { Trial terminated early } \\
\text { owing to increased rate } \\
\text { of } \mathrm{CHF}\end{array}$ \\
\hline
\end{tabular}

CV, cardiovascular; CHF, congestive heart failure; EU, European Union; GI, gastro-intestinal; Hb, haemoglobin; HDL, high-density lipoprotein; MI, myocardial infarction; RAASi, renin-angiotensin-aldosterone system inhibitor. ${ }^{*}$ The number of patients in each trial and the year of termination or publication are shown in brackets. ${ }^{\ddagger}$ Off-target effects that may offset the on-target parameter are shown. ${ }^{\S}$ Indicates the parameter the drug is targeted to. For reference details, see Supplementary information S1 (table).

blood-pressure-lowering or a lipid-lowering agent, but as a cardiovascular/renal protective agent (on the basis of multiple effects). This would also imply a change in the labelling of a drug. Thus, assuming the necessary evidence was gathered during clinical development, at marketing authorization, the drug could receive the label 'cardiovascular/renal protective drug', instead of a blood-pressure-lowering or cholesterol-lowering drug and would be prescribed to the appropriate patients based on their cardiovascular/renal risk.
Integrated score to estimate drug efficacy Clearly, for such an approach to work, a surrogate that provides a reliable estimation of the drug effect on cardiovascular/renal outcomes is needed for drug discovery, dosing, and efficacy monitoring in clinical trials. 
Such a surrogate would involve the integration of multiple short-term effects of a drug a composite response score. Just like risk scores that predict cardiovascular/renal risk for individual patients, the response score would need to include all parameters that contribute to the risk of an individual and would need to relate the change in these parameters to the ultimate cardiovascular/ renal outcome.

We have developed such a composite multiple Parameter Response Efficacy score (PRE-score). This PRE-score involves both on-target and many off-target drug responses and integrates these into a score that aims to reflect the likelihood of longterm cardiovascular/renal risk change. The score, which is described in detail in Supplementary information S3 (box), was developed and validated by using data from trials of RAAS inhibitors and performed much better in predicting the effect of a drug on cardiovascular/renal morbidity and mortality than changes in single on-target or single off-target risk markers, in both a retrospective ${ }^{15}$ and a prospective applica$\operatorname{tion}^{16}$. If the score is similarly predictive for other classes of drugs, it could provide early guidance for drug developers on which drug or which dose has the most potential to gain regulatory approval. It may also help in making well-informed regulatory decisions on novel drugs and in more effectively estimating the overall effect of the prescribed drug (or drugs) in clinical practice.

\section{Concluding remarks}

The recent expensive failures and the high drug attrition rates in late-stage cardiovascular drug development indicate that a rethinking of the strategies for developing such drugs is needed. Although it is wellknown that such drugs have multiple effects, the off-target effects are not systematically assessed when evaluating ultimate patient outcomes, and, as we have highlighted here, ignoring these off-target effects profoundly affects drug development. We advocate an integrated approach accounting for the on-target and off-target drug effects with a multiple PRE-score in order to obtain an early and more accurate estimation of the overall effect of the drug on long-term clinical outcomes. This could not only help improving drug development and registration but may also improve drug prescribing and monitoring in clinical practice.

Hiddo J. Lambers Heerspink and Dick de Zeeuw are at the Department of Clinical Pharmacy and Pharmacology, University Medical Center Groningen, University of Groningen, Antonius Deusinglaan 1, 9713 AV, Groningen, the Netherlands.

Diederick E. Grobbee is at the Julius Center for Health Science and Primary Care, University Medical Center Utrecht, Utrecht, the Netherlands.

Correspondence to H.J.L.H. e-mail: h.j.lambers.heerspink@umcg.nl doi: 10.1038/nrd4090-c2

1. Arrowsmith, J. \& Miller, P. Phase II and Phase III attrition rates 2011-2012. Nature Rev. Drug Discov. 12, 569 (2013).

2. Prentice, R. L. Surrogate endpoints in clinical trials: definition and operational criteria. Stat. Med. 8, 431-440 (1989).

3. Eijkelkamp, W. B. et al. Albuminuria is a target for renoprotective therapy independent from blood pressure in patients with type 2 diabetic nephropathy: post hoc analysis from the Reduction of Endpoints in NIDDM with the Angiotensin II Antagonist Losartan (RENAAL) trial. J. Am. Soc. Nephrol. 18, 1540-1546 (2007)

4. Jafar, T. H. et al. Proteinuria as a modifiable risk factor for the progression of non-diabetic renal disease. Kidney Int. 60, 1131-1140 (2001).

5. de Zeeuw, D. et al. Albuminuria, a therapeutic target for cardiovascular protection in type 2 diabetic patients with nephropathy. Circulation 110, 921-927 (2004)

6. Albert, M. A., Danielson, E., Rifai, N. \& Ridker, P. M Effect of statin therapy on C-reactive protein levels: the pravastatin inflammation/CRP evaluation (PRINCE): a randomized trial and cohort study. JAMA 286, 64-70 (2001).
7. Savarese, G. et al. Effects of atorvastatin and rosuvastatin on renal function: a meta-analysis Int. J. Cardiol. 167, 2482-2489 (2013).

8. Ridker, P. M. et al. Reduction in C-reactive protein and LDL cholesterol and cardiovascular event rates after initiation of rosuvastatin: a prospective study of the JUPITER trial. Lancet 373, 1175-1182 (2009).

9. De Jager, J. et al. Effects of short-term treatment with metformin on markers of endothelial function and inflammatory activity in type 2 diabetes mellitus: a randomized, placebo-controlled trial. J. Intern. Med. 257, 100-109 (2005).

10. Bailey, C. J., Gross, J. L., Pieters, A., Bastien, A. $\&$ List, J. F. Effect of dapagliflozin in patients with type 2 diabetes who have inadequate glycaemic control with metformin: a randomised, double-blind, placebo-controlled trial. Lancet 375, 2223-2233 (2010).

11. Nauck, M. A. et al. Dapagliflozin versus glipizide as add-on therapy in patients with type 2 diabetes who have inadequate glycemic control with metformin: a randomized, 52-week, double-blind, active-controlled noninferiority trial. Diabetes Care 34, 2015-2022 (2011).

12. Miao, Y. et al. Increased serum potassium affects renal outcomes: a post hoc analysis of the Reduction of Endpoints in NIDDM with the Angiotensin II Antagonist Losartan (RENAAL) trial. Diabetologia 54, 44-50 (2011).

13. Hou, F. F. et al. Renoprotection of Optimal Antiproteinuric Doses (ROAD) Study: a randomized controlled study of benazepril and losartan in chronic renal insufficiency. J. Am. Soc. Nephrol. 18, 1889-1898 (2007).

14. Lambers Heerspink, H. J. et al. The effect of ramipril and telmisartan on serum potassium and its association with cardiovascular and renal events: results from the ONTARGET trial. Eur. J. Prev. Cardiol. 21, 299-309 (2014).

15. Smink, P. A. et al. The importance of short-term off-target effects in estimating the long-term renal and cardiovascular protection of angiotensin receptor blockers. Clin. Pharmacol. Ther. 95, 208-215 (2014).

16. Smink, P. A. et al. A prediction of the renal and cardiovascular efficacy of aliskiren in ALTITUDE using short-term changes in multiple risk markers. Eur. J. Preventive Cardiol. 21, 434-441 (2014).

Acknowledgements

This work was performed as part of the Escher project (project number T6-202) within the framework of the Dutch Top Institute Pharma. H.J.L.H. is supported by a VENI-Grant from the Netherlands Organisation for Scientific Research.

\section{Competing interests statement}

The authors declare no competing interests.

SUPPLEMENTARY INFORMATION

See online article: $\underline{\mathrm{S} 1}$ (table) $\mid \underline{\mathrm{S} 2}$ (box) $\mid \underline{\mathrm{S} 3}$ (box)

ALL LINKS ARE ACTIVE IN THE ONLINE PDF 